\title{
Suppression of Root Nodule Formation by Artificial Expression of the TrEnodDR1 (Coat Protein of White clover cryptic virus 1) Gene in Lotus japonicus
}

\author{
Mitsumi Nakatsukasa-Akune, ${ }^{1}$ Kenji Yamashita, ${ }^{1}$ Yoshikazu Shimoda, ${ }^{1}$ Toshiki Uchiumi, ${ }^{2}$ \\ Mikiko Abe, ${ }^{2}$ Toshio Aoki, ${ }^{3}$ Ayumi Kamizawa, ${ }^{3}$ Shin-ichi Ayabe, ${ }^{3}$ Shiro Higashi, ${ }^{2}$ and Akihiro Suzuki ${ }^{2}$ \\ ${ }^{1}$ Graduate School of Science and Technology, Kagoshima University, Kagoshima 890-0065, Japan; ${ }^{2}$ Department of Chemistry \\ and Bioscience, Faculty of Science, Kagoshima University, Kagoshima 890-0065, Japan; ${ }^{3}$ Department of Applied Biological \\ Sciences, Nihon University, Kanagawa, 252-8510, Japan
}

Submitted 18 March 2005. Accepted 14 June 2005.

\begin{abstract}
TrEnodDR1 (Trifolium repens early nodulin downregulation 1) encodes a coat protein of White clover cryptic virus 1. Its expression in white clover was down-regulated at the time when root nodules formed. We surmised that its artificial expression would interfere with root nodulation. Therefore, we investigated the effects of its artificial expression on the growth and root nodulation of Lotus japonicus (a model legume). Transformants were prepared by Agrobacterium spp.-mediated transformation. The growth of transformants was reduced and the number of root nodules per unit root length was greatly decreased relative to control. The concentration of endogenous abscisic acid (ABA), which controls nodulation, increased in plants containing TrEnodDR1. These phenotypes clearly were canceled by treatment with abamine, a specific inhibitor of ABA biosynthesis. The increase in endogenous $\mathrm{ABA}$ concentration explained the reduced stomatal aperture and the deformation of root hairs in response to inoculation of transgenic $L$. japonicus with Mesorhizobium loti. Transcriptome comparison between TrEnodDR1 transformants and control plants showed clearly enhanced expression levels of various defense response genes in transformants. These findings suggest that TrEnodDR1 suppresses nodulation by increasing the endogenous $\mathrm{ABA}$ concentration, perhaps by activating the plant's innate immune response. This is the first report of the suppression of nodulation by the artificial expression of a virus coat protein gene.
\end{abstract}

Additional keywords: abscisic acid, symbiosis.

To establish the symbiosis responsible for nitrogen fixation, compatible rhizobia and leguminous plant partners recognize each other through the exchange of chemical signals (Hayashi et al. 2000; Hirsch et al. 2003). Rhizobia produce and secrete the nodulation (Nod) factor in response to plant compounds that induce bacterial nod genes. The Nod factor induces root

Corresponding author: Akihiro Suzuki; Address: 1 Honjyo-machi, Saga City, Saga 840-8502, Japan; Telephone: +81-952-28-8721; Fax: +81-95228-8721; E-mail: azuki@cc.saga-u.ac.jp

Current address for A. Suzuki: Department of Agricultural Sciences, Faculty of Agriculture, Saga University, Saga 840-8502, Japan.

Current address for Y. Shimoda: Kazusa DNA Research Institute, Chiba 292-0812, Japan. hair deformation and curling, and cortical cell division leading to the formation of nodule primordia. Rhizobia arrive in nodule primordia through an infection thread formed in the curled root hair, becoming a specialized form called a "bacteroid", which then differentiates into nitrogen-fixing forms. In the root nodules, the rhizobia convert atmospheric nitrogen into nitrogen-containing compounds and pass them to the host plant as a source of nitrogen. In return, the host plant supplies photosynthates to the rhizobia as a carbon source.

Despite the beneficial aspects of this symbiosis, too many root nodules can unbalance demand and supply and disrupt the growth of host plants (Nishimura et al. 2002b). To suppress excessive root nodulation, plants use autoregulation. Hypernodulating mutants in which autoregulation has failed have been reported in several legumes, such as ntsl in Glycine max, harl in Lotus japonicus, and sym 29 in Pisum sativum. Genes responsible for these mutants encode receptor-like kinases similar to CLV1, which controls meristem cell number and differentiation in Arabidopsis spp. (Krusell et al. 2002; Nishimura et al. 2002a; Searle et al. 2003).

Control of root nodule number by phytohormones is another mechanism. The plant hormone ethylene is well known as a negative regulator of root nodule formation (Ma et al. 2003; Nukui et al. 2000; Oldroyd et al. 2001). The hypernodulation mutant sickle of Medicago truncatula is insensitive to ethylene (Penmetsa and Cook 1997). Moreover, formation of infection threads and nodule primordia were enhanced in the roots of transgenic L. japonicus with an added ethylene receptor gene (Nukui et al. 2004).

The phytohormone abscisic acid (ABA) plays a major role in adaptation to environmental stresses, plant growth, and development (Finkelstein et al. 2002; Shinozaki and YamaguchiShinozaki 2000; Zhu 2001). Exogenous ABA decreased nodule number in some leguminous species (Bano and Harper 2002; Bano et al. 2002; Cho and Harper 1993; Phillips 1971). In L. japonicus, endogenous ABA controls the number of root nodules without affecting plant growth (Suzuki et al. 2004).

We previously reported that Trifolium repens early nodulin downregulation 1 (TrEnodDR1), isolated from a cDNA library prepared from white clover (Trifolium repens), was downregulated in response to expression of the nod genes of Rhizobium leguminosarum bv. trifolii strain 4S (Suzuki et al. 2001). Recently, an amino acid sequence identical to that of TrEnodDRl was reported as a coat protein (CP) of White clover cryptic virus 1 (WCCV1) (Boccardo and Candresse 2005). This virus inhabits the seedlings of white clover and the tran- 
script of the $\mathrm{CP}$ gene has a poly $(\mathrm{A})^{+}$tail, making it suitable as a template for reverse transcription; therefore, it is possible that TrEnodDRl derives from WCCV1 in white clover. Because its expression in white clover was down-regulated at the time when root nodules formed, we surmised that its artificial expression would interfere with root nodulation. Therefore, we investigated the effect of its artificial expression on the growth and root nodule formation of L. japonicus (a model legume). In transgenic L. japonicus containing $\operatorname{TrEnodDR} 1$, root nodule formation was suppressed by an increase in endogenous ABA concentration, possibly caused by the expression of defenseresponse genes in response to the viral $\mathrm{CP}$.

\section{RESULTS}

Transformation of hairy roots of $L$. japonicus with TrEnodDR1.

In order to study the effect of TrEnodDR1, L. japonicus was transformed by Agrobacterium spp.-mediated transformation. Plasmid pHKN29-DR1, containing the coding region for green

\section{pHKN29-DR1}

BL

BR

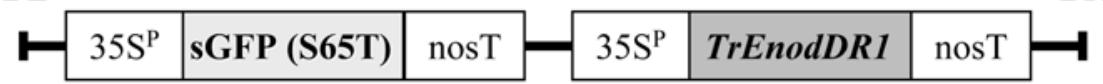

pIG121-Hm-DR1

BR

BL

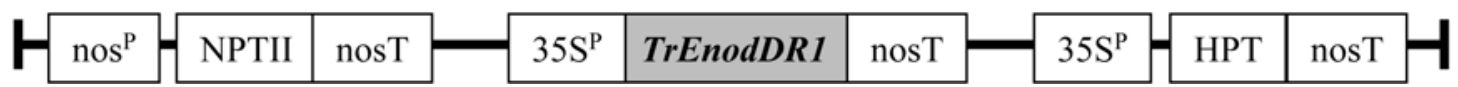

Fig. 1. Schematic diagrams of T-DNA region of binary vector for transformation of Lotus japonicus.

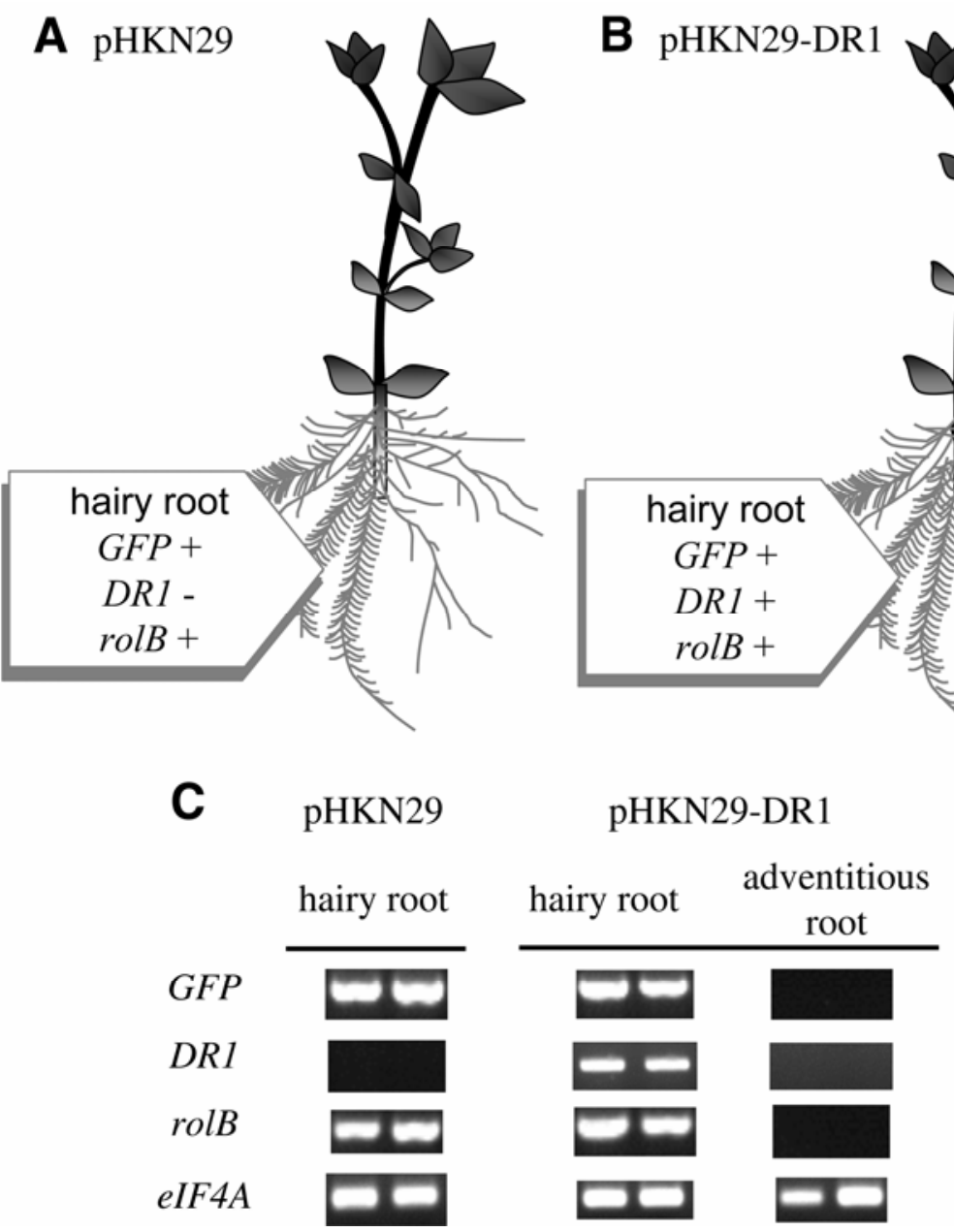

Fig. 2. Schematic representation of Lotus japonicus with transformed hairy roots and expression profiles of introduced genes. A and $\mathbf{C}$, pHKN29, plants treated with Agrobacterium rhizogenes containing plasmid pHKN29. B and C, pHKN29-DR1, plants treated with A. rhizogenes containing plasmid pHKN29-DR1 B, Gray roots are hairy roots with green fluorescent protein fluorescence; black roots are adventitious roots. Expressed and unexpressed genes are marked "+" and "-", respectively. C, Agarose gel electrophoresis of reverse-transcriptase polymerase chain reaction product. Expression of four genes in each root was analyzed in each experiment, two samples each. The eIF4A gene was used as an internal control. 
fluorescent protein $(s G F P)$ and the coding region of TrEnodDR1, was constructed for this purpose (Fig. 1). Plasmid pHKN29, containing $s G F P$ only, was used as an empty vector for the generation of control hairy roots. GFP fluorescence (Niwa et al. 1999) clearly was visible in all emerged hairy roots of both transformants, indicating correct transformation. However, transformants containing TrEnodDRl produced hairy roots showing GFP fluorescence (DR1 hairy roots) and adventitious roots not showing it (Fig. 2A and B). Expression profiles of introduced genes were analyzed in control hairy roots, DR1 hairy roots, and adventitious roots by reverse-transcriptase polymerase chain reaction (RT-PCR). Amplified DNA fragments derived from GFP mRNA were detected only in roots which showed GFP fluorescence (control and DR1
A
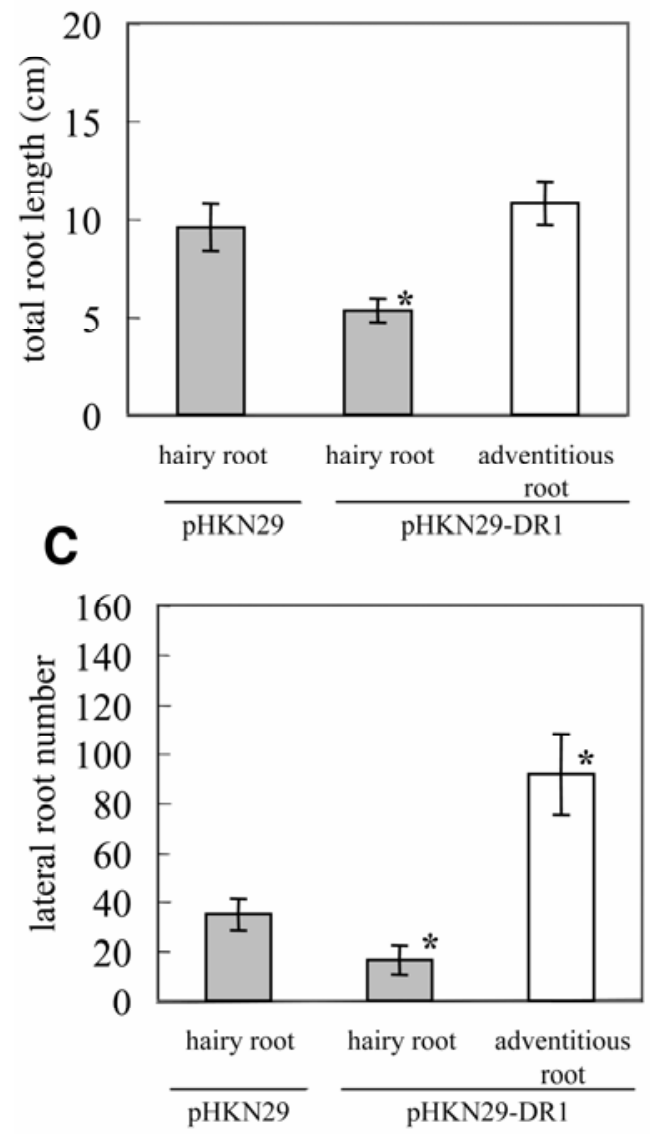

B
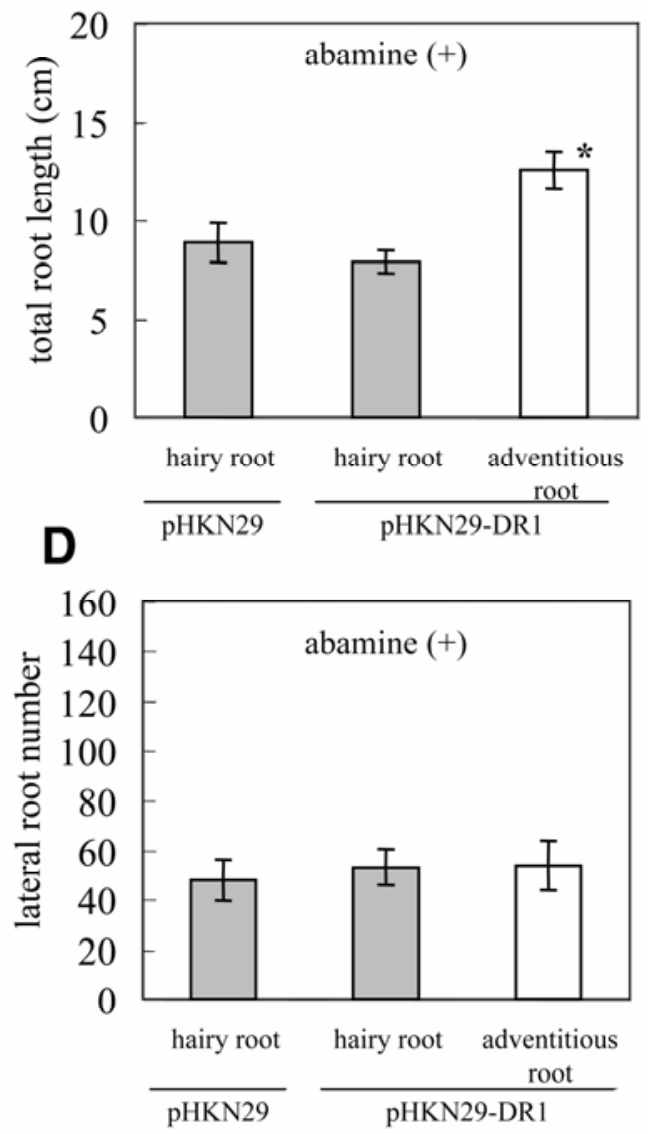

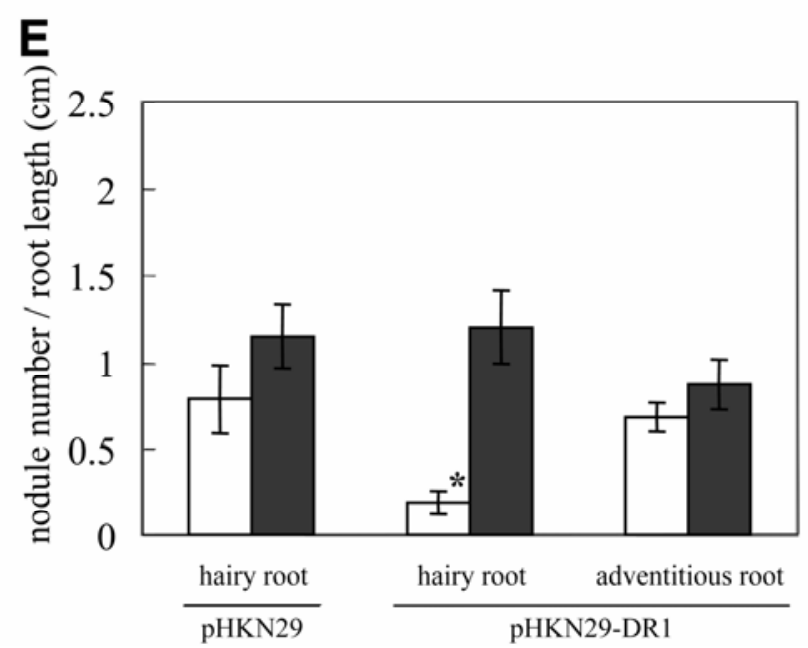

Fig. 3. Effects of overexpression of TrEnodDR1 on the growth of roots and nodulation of Lotus japonicus 28 days after inoculation. Each experiment was carried out three times. At least 15 plants were used in each experiment. Error bars indicate standard error, and statistical significance is indicated by asterisks $(P<0.05)$. A-D, Gray bars, hairy roots; open bars, adventitious roots. E, Open bars, no abamine treatment; filled bars, with abamine treatment. A and $\mathbf{B}$, Total root length. $\mathbf{C}$ and $\mathbf{D}$, Lateral root number. E, Average number of root nodules per unit root length. Open bars, no abamine treatment; filled bars, with abamine treatment. B and $\mathbf{D}$, Abamine $(10 \mu \mathrm{M})$ was used to decrease endogenous abscisic acid level. A through $\mathbf{E}$, pHKN29, plants treated with Agrobacterium rhizogenes containing plasmid pHKN29; pHKN29-DR1, plants treated with A. rhizogenes containing plasmid pHKN29-DR1. 
hairy roots) (Fig. 2C). The expression pattern of rolB on $\mathrm{Ri}$ plasmid was the same. TrEnodDRl was detected only in the DR1 hairy roots (Fig. 2A and B). Hairy root which had the rolB gene without GFP was not observed in this experiment.

\section{Effect of TrEnodDR1 on the root growth}

and root nodule formation on transformed hairy root.

At 28 days after inoculation (DAI) of roots with Mesorhizobium loti MAFF303099, total root length and lateral root number were investigated. Total root length apparently was suppressed in DR1 hairy roots, and the number of lateral roots was reduced (Fig. 3A and C). To investigate the effect of artificial expression of TrEnodDRI on root nodule formation, number of nodules per unit length of root was calculated 28 DAI (Fig. 3E). Nodule number on DR1 hairy roots was much less than the control. Figure $4 \mathrm{~A}$ and $\mathrm{B}$ shows nodules formed on the control hairy roots, and Figure 4E and $\mathrm{F}$ shows suppressed root nodule formation on DR1 hairy roots. However, the nodule number on adventitious roots was almost the same as that on the control hairy roots (Fig. 3E).

\section{Change of ABA concentration in root system by artificial expression of TrEnodDR1.}

Previous studies with ABA have reported that the ABA concentration controls the number of root nodules (Suzuki et al. 2004). In this study, the endogenous ABA concentration of $L$. japonicus plants with transformed hairy roots was analyzed. There was no significant difference $(P>0.05)$ in ABA between control plants and DR1 plants expressing TrEnodDRl in leaves (Fig. 5A). In contrast, the concentration of ABA in DR1 hairy roots was significantly higher than that in control hairy roots and adventitious roots (Fig. 5B).
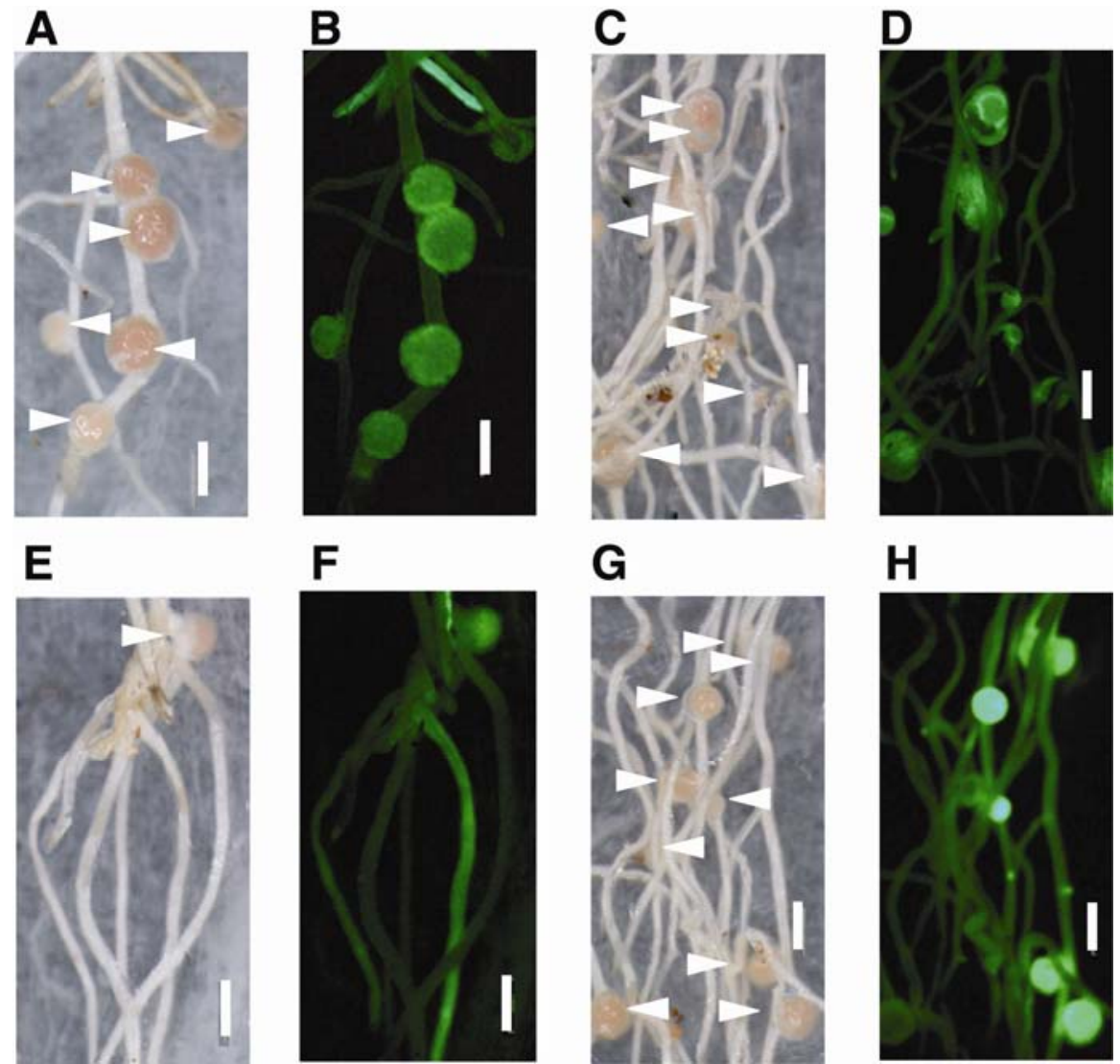

Fig. 4. Root nodules formed on transformed hairy roots at 28 days after inoculation under $\mathbf{A}, \mathbf{C}, \mathbf{E}$, and $\mathbf{G}$, bright field and $\mathbf{B}, \mathbf{D}, \mathbf{F}$, and $\mathbf{H}$, fluorescence microscopy. A and $\mathbf{B}$, Control hairy roots without abamine. $\mathbf{C}$ and $\mathbf{D}$, Control hairy roots with abamine. $\mathbf{E}$ and $\mathbf{F}$, DR1 hairy roots without abamine. $\mathbf{G}$ and $\mathbf{H}$, DR1 hairy roots with abamine. White arrowheads show nodules. Scale bars $=1 \mathrm{~cm}$. 
hair curling. On the other hand, the proportion of wavy root hairs on DR1 hairy roots was much higher without abamine treatment (Fig. 6C and E). It was similar to that of ABAtreated root hairs of wild-type L. japonicus inoculated by rhizobia. In root hairs treated with $0.05 \mu \mathrm{M}$ ABA, the proportion of wavy root hairs increased (Fig. $6 \mathrm{H}$ and I). However, when DR1 hairy roots were treated with abamine, the proportion of wavy root hairs clearly was decreased and the proportion of curling root hairs was recovered (Fig. 6C and G).

\section{Effect of TrEnodDRI on growth and root nodule formation} of whole-plant transformants of $L$. japonicus.

One-step RT-PCR was used to analyze the expression of transgenes in plant cuttings rooted artificially to synchronize their growth. Amplified DNA fragments were detected in transformants but not in wild-type controls (Fig. 7A). To investigate the effects of the introduced gene on plant growth, shoot length, root length, lateral root number, and fresh weight of plants were measured 28 DAI. Control transformants containing only 35SGUS did not differ from the wild type. On the other hand, the shoot length of TrEnodDRI transformants clearly was less than the transformed control and wild-type control (Fig. 7B). Root length, lateral root number, and fresh weight were affected by TrEnodDR1 depending on the transgenic line (Fig. 7C, D, and E). The root length of line $\mathrm{H} 21$ was suppressed (Fig. 7C) and the fresh weight of line I2 clearly was decreased (Fig. 7E). To investigate the effect of overexpression of TrEnodDRl on root nodule formation, the nodule number per plant was counted 28 DAI using whole-plant transformants. In all TrEnodDRl transformants, the nodule number was much less than in the wildtype and control transformants (35S-GUS) (Fig. 7F).

\section{Effect of abamine treatment on root nodule formation in whole-plant transformants.}

To confirm whether the suppression of nodule number was due to $\mathrm{ABA}$, the endogenous $\mathrm{ABA}$ concentration was measured in three transgenic lines (H1, I2, and J6). The ABA concentration of all three transgenic lines increased compared with the wild-type control (Fig. 8C). Moreover, this increase was completely recovered by the addition of $10 \mu \mathrm{M}$ abamine. Similarly, nodule number per root and nodule number per unit length also were recovered (Fig. 8A and B).
Effect of overexpression of TrEnodDRI on stomatal aperture in whole-plant transformants.

The stomatal aperture (width by length) and endogenous ABA concentrations of transgenic L. japonicus leaves were measured. The stomatal aperture of TrEnodDRl transformants was reduced compared with wild-type and 35S-GUS controls (Fig. 9A), and the endogenous ABA concentration was increased (Fig. 9B).

\section{Induction of defense response genes \\ in transgenic L. japonicus with TrEnodDR1.}

Eight defense response genes were selected as up-regulated genes in TrEnodDRl transformants by cDNA macroarray analysis (data not shown). To confirm their expression, quantitative real-time RT-PCR was conducted. All eight genes clearly were up-regulated in transgenic L. japonicus with TrEnodDRl (Fig. 10). In particular, the expression levels of bet $v 1$, thaumatinlike protein, chalcone synthase, caffeic acid O-methyltransferase, and class I chitinase were 10 or more times that of the wild type. These enhanced expressions were recovered to some extent by $10 \mu \mathrm{M}$ abamine treatment except for thaumatine-like protein gene.

\section{DISCUSSION}

At the time this study was started, no known gene homologous to TrEnodDRl was found through database searches based on the nucleotide sequence. Therefore, we were unable to isolate orthologs of TrEnodDRl by the screening of a cDNA library of L. japonicus probed with cDNA of TrEnodDRI gene. In addition, we could not detect any significant bands by genomic Southern hybridization using cDNA of TrEnodDRl to probe several legume species (data not shown). Hence, the function of TrEnodDRl was unknown.

However, we believed that this gene should negatively affect root nodulation, because its expression decreased just when root nodules formed (Suzuki et al. 2001). If this idea was correct, artificial expression of TrEnodDRl at the time when its expression was originally suppressed should have negative effects on root nodulation. Effective methods of transformation have not been established for white clover, from which this gene was isolated; therefore, model legume L. japonicus was used (Aoki et al. 2003; Kumagai and Kouchi 2003).

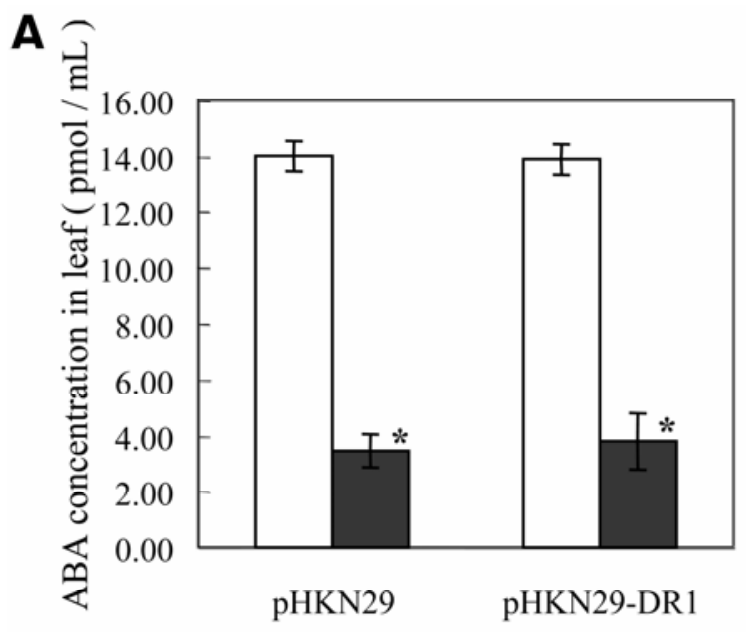

Fig. 5. Effects of exogenous abamine on endogenous abscisic acid (ABA) concentration in A, leaves and B, roots of Lotus japonicus 28 days after inoculation. Each experiment was carried out three times. At least 15 plants were used in each experiment. Open bars, no abamine treatment; filled bars, with abamine treatment. Error bars indicate standard error, and statistical significance is indicated by asterisks $(P<0.05)$. pHKN29, plants treated with Agrobacterium rhizogenes containing plasmid pHKN29; pHKN29-DR1, plants treated with A. rhizogenes containing plasmid pHKN29-DR1.

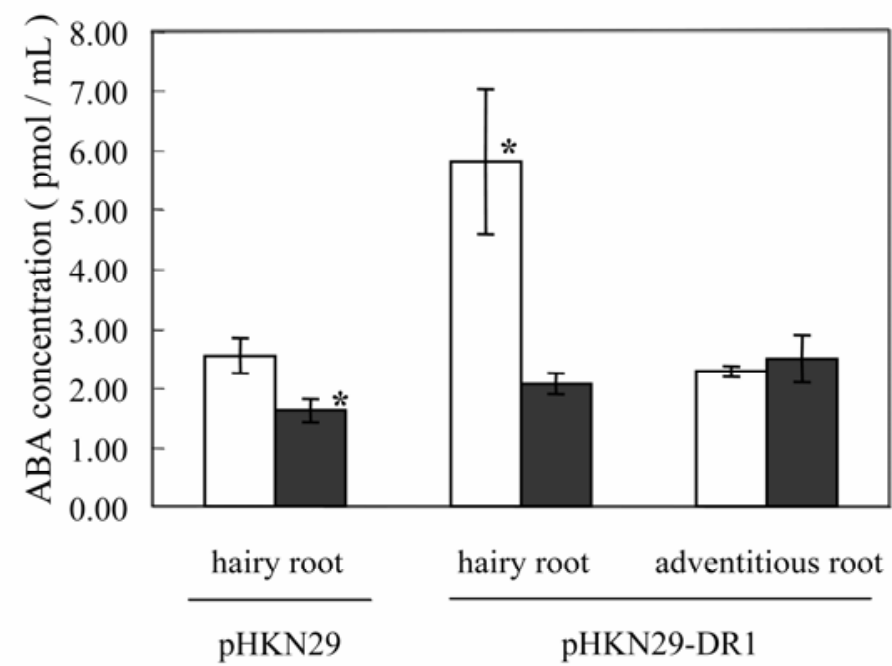

Vol. 18, No. 10, 2005 / 1073 
Because inoculation with $M$. loti MAFF303099 of emerged hairy roots of L. japonicus transformed by Agrobacterium rhizogenes LBA1334 produces effective root nodules (Kumagai and Kouchi 2003), this same system was adapted to examine the expression of TrEnodDRl in this study. The binary vectors we used contain the coding region for GFP (Fig. 1A and B); therefore, transformed hairy roots are easily distinguishable by GFP fluorescence (Fig. 4). Both hairy roots showing GFP fluores-
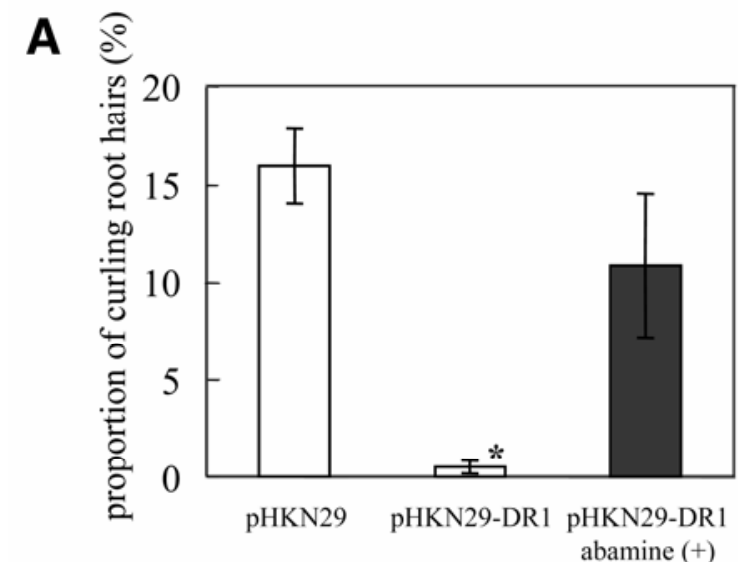

C
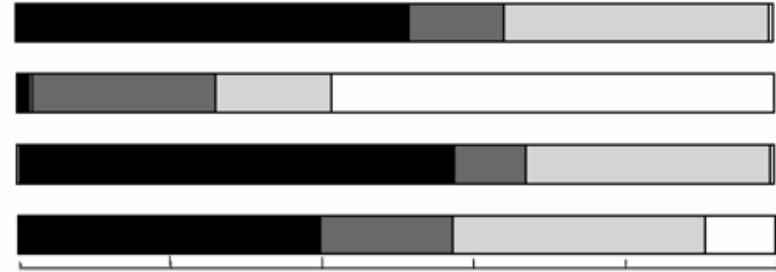

$0 \%$
B

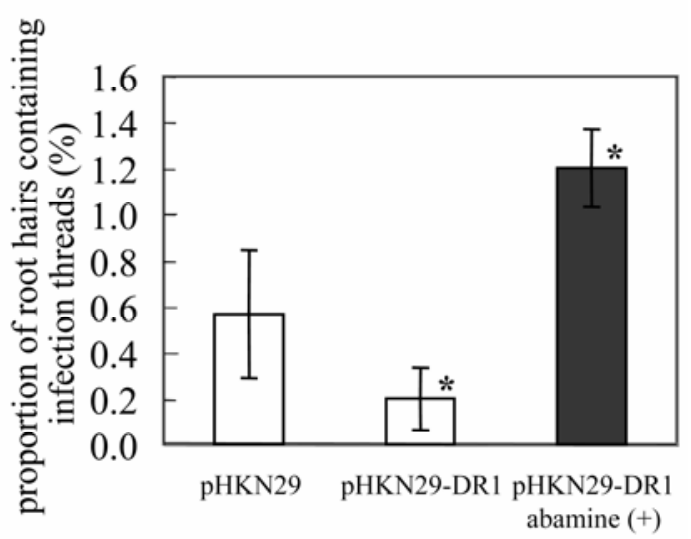

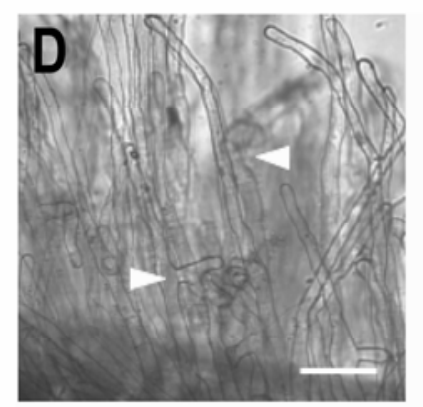
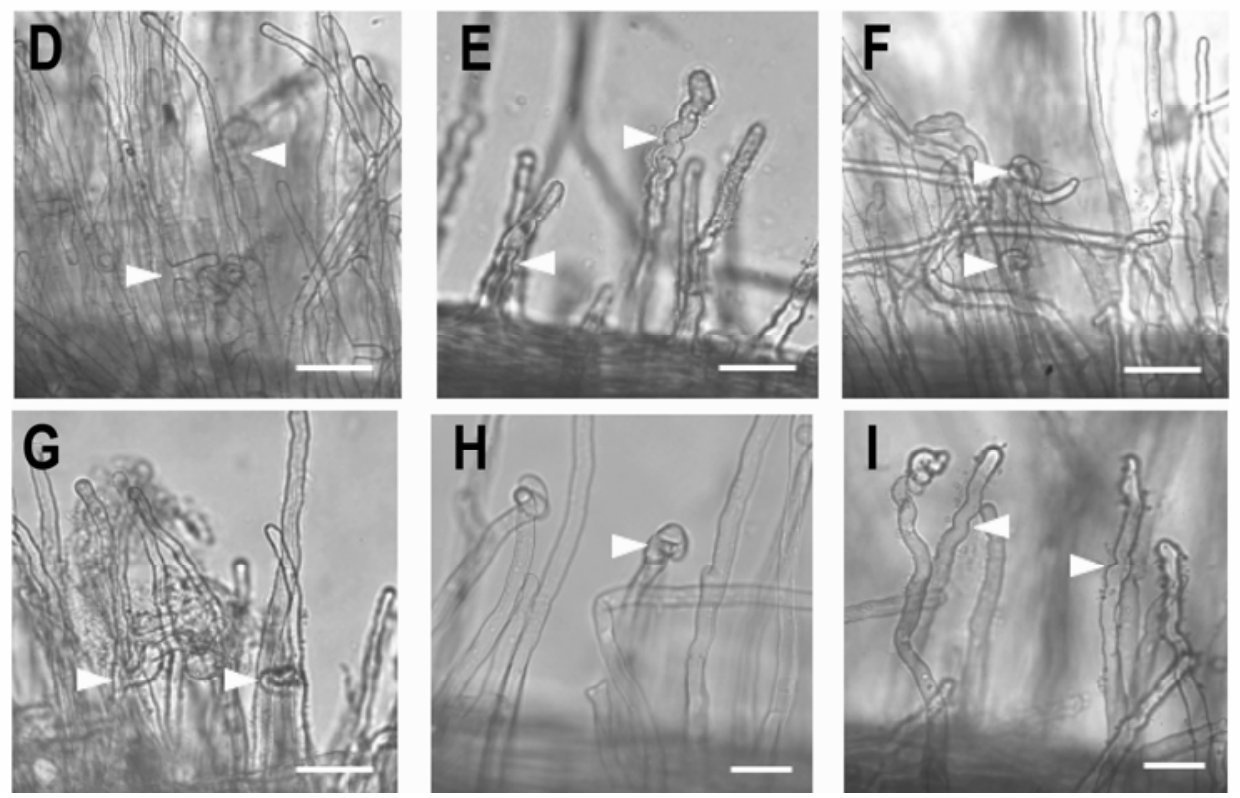

Fig. 6. Effects of overexpression of TrEnodDRl on the phenotype of root hairs with or without abamine treatment in transformed hairy roots. A, Proportion of curled root hairs. Error bars indicate standard error, and statistical significance is indicated by asterisks $(P<0.05)$. B, Proportion of root hairs containing infection threads. Error bars indicate standard error, and statistical significance is indicated by asterisks $(P<0.05)$. C, Proportion of curled, swollen, branched, or wavy root hairs in all deformed root hairs. D-G, Photomicrographs of typical root hairs of transformed hairy roots. Scale bars $=100 \mu \mathrm{m}$. D, Control hairy roots without abamine. White arrowheads show curled root hairs. E, DR1 hairy roots without abamine. White arrowheads show wavy root hairs. F, Control hairy roots with abamine. White arrowheads show curled root hairs. G, DR1 hairy roots with abamine. White arrowheads show curled root hairs. H, Typical root hairs of wild-type Lotus japonicus. White arrowhead shows curled root hair. Scale bars $=50 \mu \mathrm{m}$. I, Wavy root hairs of wild-type $L$. japonicus treated with $0.05 \mu \mathrm{M}$ abscisic acid. White arrowheads show wavy root hairs. Scale bars $=50 \mu \mathrm{m}$. 
cence (DR1 hairy roots) and adventitious roots showing no GFP fluorescence emerged from plants transformed with plasmid pHKN29-DR1, but control plants (transformed with plasmid pHKN29) produced only GFP hairy roots (control hairy roots)
(Fig. 2A and B). DR1 hairy roots of transformants accounted for approximately $35 \%$ of total root length, and adventitious roots accounted for approximately 65\% (Fig. 3A). This result indicates that the emergence of hairy roots was suppressed by the

A
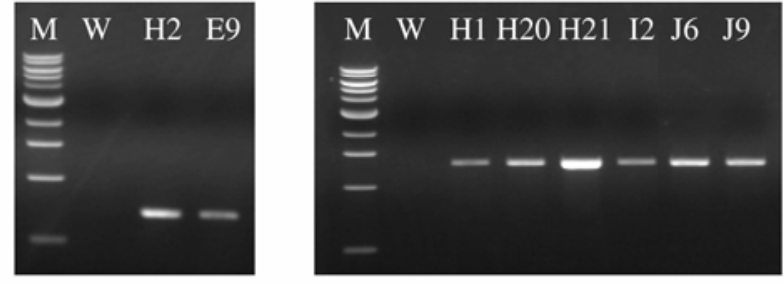

B
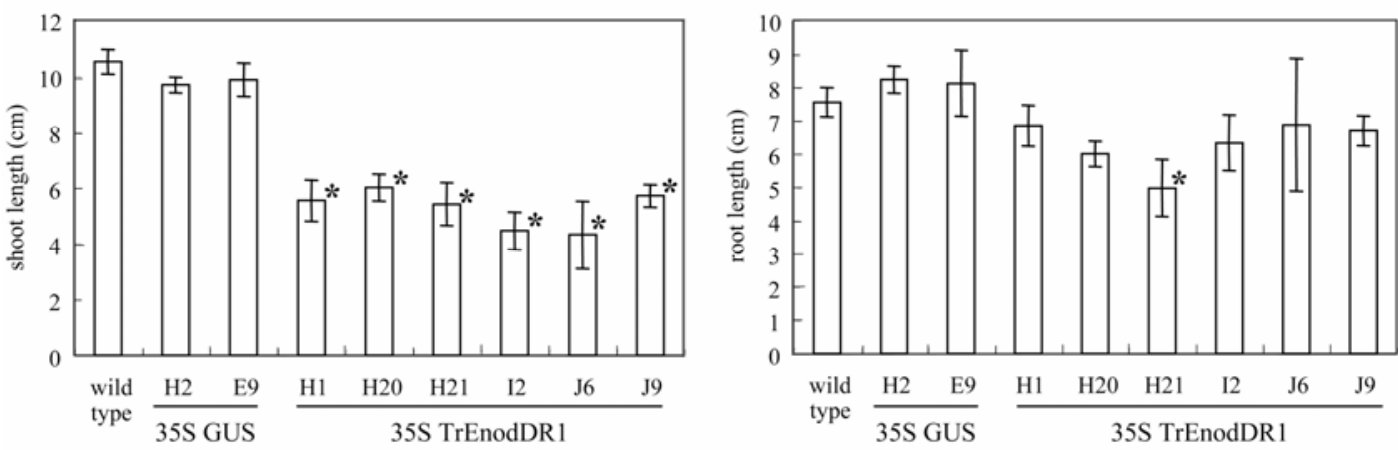

D

E
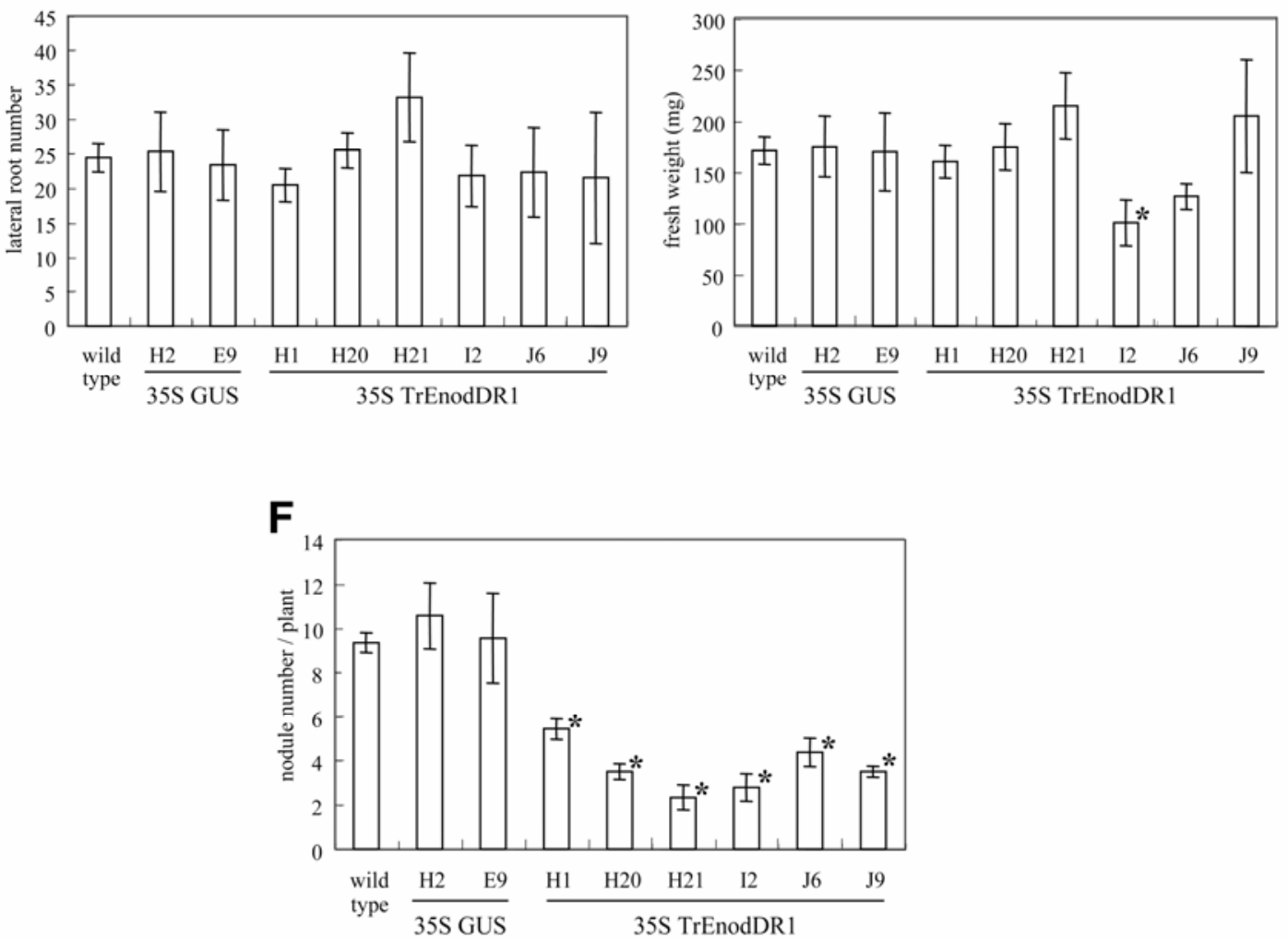

Fig. 7. Expression of introduced genes and effects of overexpression of TrEnodDR1 on the growth of Lotus japonicus 28 days after inoculation. A, Agarose gel electrophoresis of reverse-transcriptase polymerase chain reaction product. Expression of GUS (H2 and E9) and $\operatorname{TrEnodDR1}$ (H1, H20, H21, I2, J6, and J9) was analyzed. W, wild-type L. japonicus; M, DNA size marker. B, Shoot length. C, Total root length. D, Lateral root number. E, Fresh weight. F, Average number of root nodules per plant. B through $\mathbf{F}$, Error bars indicate standard error, and statistical significance is indicated by asterisks $(P<0.05)$. 
artificial expression of TrEnodDRl, and adventitious roots emerged to compensate. Further, the total length of DR1 hairy roots was much less than that of control hairy roots (Fig. 3A), and the number of lateral roots of DR1 hairy roots also was reduced. These results suggest that artificial expression of TrEnodDR1 reduces the growth and branching of hairy roots.

As expected, DR1 plants had significantly fewer root nodules per plant than control plants (Figs. 4A, B, E, and F and
$7 F)$. It was possible that this decrease was due to reduction of the nodulation zone caused by poor growth of DR 1 hairy roots; therefore, we calculated the number of nodules per unit length of hairy roots. (Fig. 3E). Because the root nodule number per unit length of DR1 hairy roots was much less than in the control, this possibility was rejected. These results show that artificial expression of TrEnodDRl reduced root nodule formation.

A

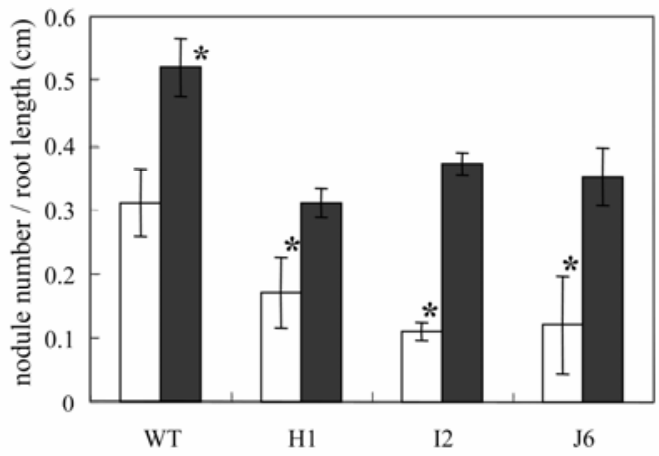

B

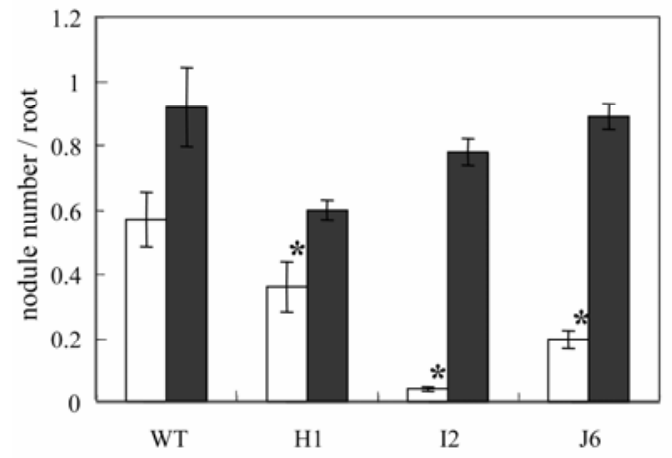

C

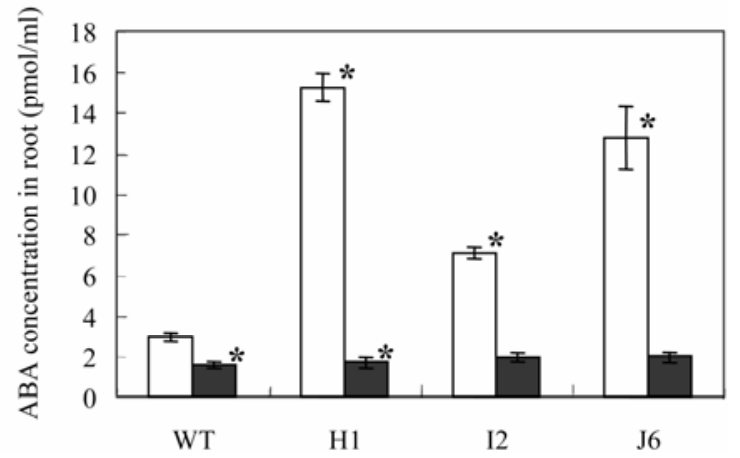

Fig. 8. Effects of overexpression of TrEnodDR1 on the nodulation and endogenous abscisic acid (ABA) concentration of whole-plant transformants 28 days after inoculation. Each experiment was carried out three times. At least 15 plants were used in each experiment. Open bars, no abamine treatment; filled bars, with abamine treatment; WT, wild-type Lotus japonicus; H1, I2, and J6, transformed L. japonicus. Error bars indicate standard error, and statistical significance is indicated by asterisks $(P<0.05)$. A, Average number of root nodules per unit root length. B, Average number of root nodules per root. $\mathbf{C}$, ABA concentration in roots.

A

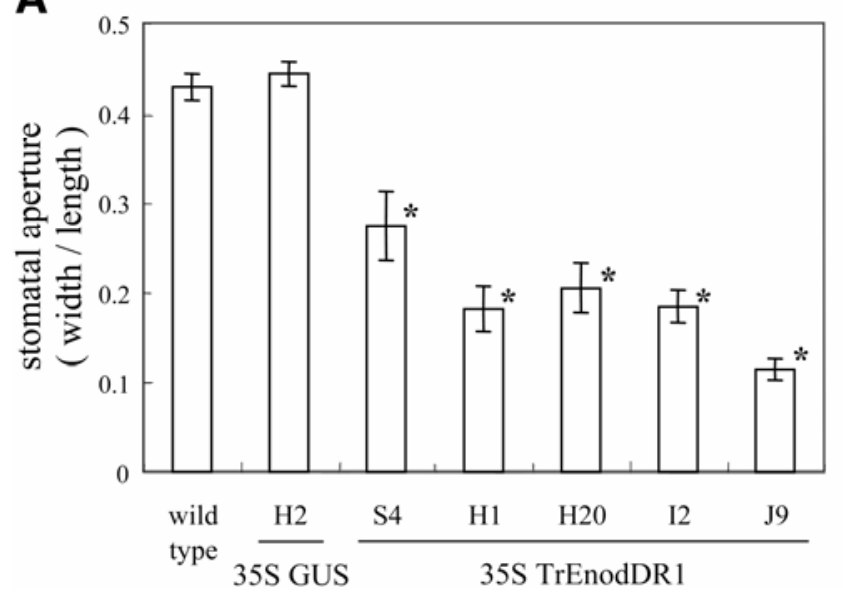

B

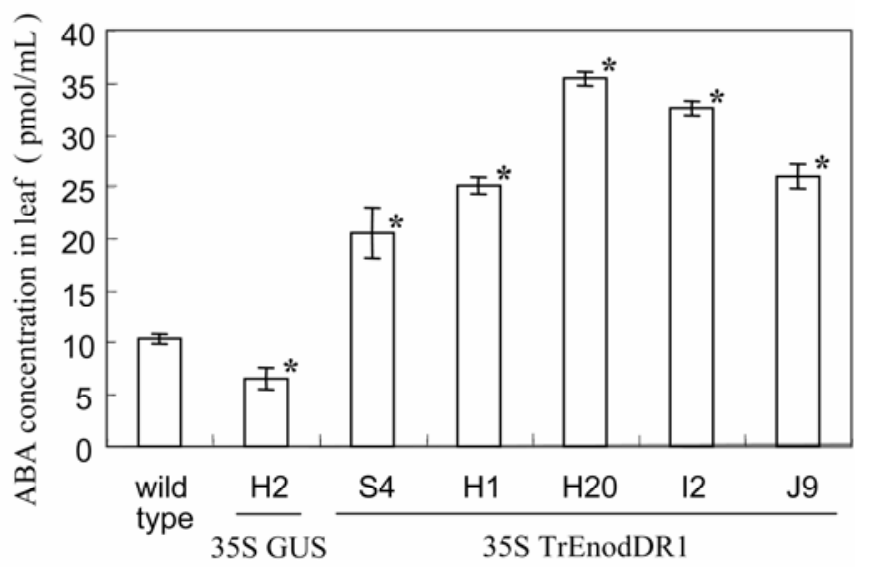

Fig. 9. Effect of overexpression of TrEnodDRl on stomatal aperture in Lotus japonicus. Leaves of transformants were put on a slide glass coated with spray paste to get an impression of the epidermis. The impression then was observed under the microscope. H2: 35S-GUS transformant. S4, H1, H20, I2, and J9: DR1 transformants. Error bars indicate standard error, and statistical significance is indicated by asterisks $(P<0.05)$. A, Stomatal aperture. Each experiment was carried out three times. At least five plants were used in each experiment. B, Endogenous abscisic acid concentration of leaves. 
It is well known that the concentration of ABA affects nodule number in several species (Bano and Harper 2002; Bano et al. 2002; Phillips 1971), including L. Japonicus (Suzuki et al. 2004). Therefore, we investigated whether the decrease of nodule number on the DR1 hairy roots was due to an increase in endogenous ABA concentration. There was no difference in the ABA concentration in leaves between control and DR1 plants (Fig. 5A). However, the endogenous ABA concentration of DR1 hairy roots was much greater than that of control hairy roots (Fig. 5B). These results suggest strongly that the decrease of root nodule number on the DR1 hairy roots was caused by the increase in endogenous ABA concentration. They also suggest that $\mathrm{ABA}$ is synthesized independently in each tissue; therefore, higher concentration of $\mathrm{ABA}$ in the root does not affect the concentration in the shoot, and ABA concentration in the shoots does not affect nodulation in the roots.

If artificial expression of TrEnodDRl affects the growth of hairy roots and the number of root nodules through a change in endogenous $\mathrm{ABA}$ concentration, these effects should be reversed when the endogenous ABA concentration is decreased. We used abamine to inhibit ABA biosynthesis, as previously reported (Suzuki et al. 2004). Although abamine targets nonheme iron oxgenases called carotenoid cleavage dioxygenases (CCDs) other than NCED on ABA biosynthesis (Sun-Young et al. 2004), this inhibitor shows higher specificity to NCED on ABA biosynthesis other than CCDs (data not shown). Moreover, the effects of abamine on the growth and nodulation of leguminous plants clearly were cancelled by the treatment of ABA (Suzuki et al. 2004.). The effect of abamine was transmitted from roots to leaves regardless of the expression of TrEnodDRl in the roots (Fig. 5A). On the other hand, the ABA concentration in DR1 hairy roots treated with abamine was reduced to the level in control hairy roots and adventitious roots (Fig. 5B). These re- sults show that abamine functions not only in normal roots but also in hairy roots. The growth and number of root nodules of DR1 hairy roots clearly were recovered by treatment with abamine (Figs. 3B and E and 4C, D, G, and H). Because abamine decreased the endogenous ABA concentration, these results support the idea that overexpression of TrEnodDRl affects the growth of hairy roots and the number of root nodules by increasing the endogenous ABA concentration.

The proportions of curling root hairs and root hairs containing infection threads in DR1 hairy roots were much less than those in control hairy roots (Fig. 6A and B). This result supports the idea that the endogenous ABA concentration in DR1 hairy roots was higher than that of control hairy roots, because ABA blocks the step between root hair swelling and curling (Phillips 1971; Suzuki et al. 2004). Furthermore, ABA treatment increased the proportion of wavy root hairs in wild-type $L$. japonicus. The proportion of wavy root hairs clearly increased in DR1 hairy roots (Fig. 6C), and this increase clearly was canceled by abamine treatment. These observations indicate that the endogenous ABA concentration of DR1 hairy roots was higher than that of control hairy roots.

Hairy roots induced by Agrobacterium rhizogenes show an abnormal phytohormone balance owing to the presence of the rol genes on the Ri plasmid (Fladung 1990; Nilsson et al. 1993; Oono et al. 1987; Schmülling et al. 1988). To test whether the effect of overexpression of TrEnodDRl was due to the unbalanced phytohormone content, we tested whole-plant transgenic L. japonicus. As expected, the growth of shoots of DR1 transformants was suppressed (Figs. 7B) and the numbers of root nodules per plant and per unit length (Figs. $7 \mathrm{~F}$ and 8A) were reduced compared with those of wild-type and 35S-GUS transformants (control transformants). In the absence of abamine, the endogenous ABA concentration increased and root nodule num-

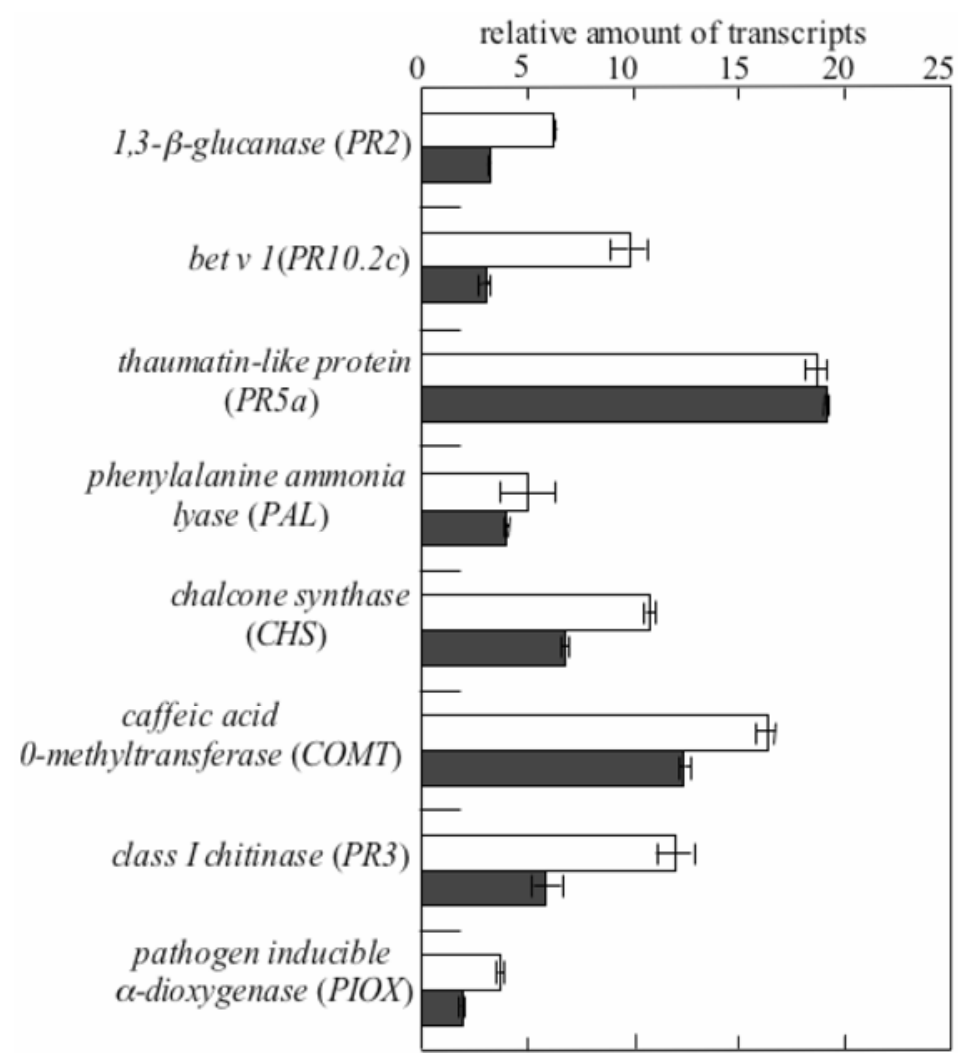

Fig. 10. Expression of defense response genes in transformed Lotus japonicus 28 days after inoculation. Amounts of transcripts were rectified against LjeIF$4 A$ (internal control) transcripts and were normalized relative to the mean value in wild-type plants, which was set to 1 . The values indicate the average of three independent experiments with standard deviations. Open bars, no abamine treatment; filled bars, with abamine treatment. 
ber decreased in the DR1 transformants (Fig. 8). These effects of TrEnodDR1 were reversed by treatment with abamine (Fig. 8). Although plants prepared from cuttings of primary transformant (first generation) were used in these experiments, the results are consistent with those in hairy roots; therefore, we judged that they are reliable and that the phytohormone imbalance was not responsible. Moreover, these results suggest that artificial expression of TrEnodDRl independently affects growth and the number of root nodules by increasing the endogenous ABA concentration.

ABA regulates stomatal apertures by inhibiting stomatal opening and inducing stomatal closure (Uno et al. 2000). Stomatal apertures of DR1 transformants clearly were smaller than those of wild-type L. japonicus or control transformants (Fig. 9A). This means that the endogenous ABA concentration of DR1 transformants was higher than that of control plants.

Some questions remain to be solved. In our ABA doseresponse experiments, root nodule number decreased as ABA concentration increased within a certain range (Suzuki et al. 2004). However, if restricted to whole-plant DR1 transformant or DR1 hairy roots, the number of root nodules was not strictly linked with endogenous ABA concentration. Moreover, stomatal aperture was not strictly linked with endogenous ABA concentration (Fig. 9A and B). These observations suggest that TrEnodDRI not only increases endogenous ABA concentration but also has other effects. To answer this question, DR1 transformants and wild-type plants were compared by transcriptome analysis (Kouchi et al. 2004). Several defenseresponse genes were up-regulated significantly (Fig. 10), as would happen in response to pathogens. If TrEnodDRl encodes a coat protein of WCCV1, such a defense response would be reasonable, because the DR1 transformants would have been producing pathogen proteins. Moreover, because these enhanced expressions were not necessarily canceled by abamine treatment (Fig. 10), this phenomenon was due to the increased endogenous ABA concentration and another unknown mechanism. Other researchers have introduced genes for viral CPs to engineer resistance to viruses (Abel et al. 1986; Beachy 1990; Jan et al. 2000a,b), but resistance is limited to the corresponding virus or closely related viruses. Ours is the first report of the suppression of root nodule formation by the artificial expression of a CP. Thus, it is likely that TrEnodDRl affects nodulation by suppression of rhizobial infection due to activation of the plant's innate immune response. Moreover, it is likely that white clover may utilize this cryptic virus to maintain the constitutive defense response.

The number of root nodules was suppressed by the overexpression of TrEnodDRl through an increase in endogenous ABA level. If leguminous species in general have such a mechanism for controlling root nodule number, genes such as ZEP and $N C E D$, which work in the ABA biosynthesis pathway, are possible candidate genes which show the same function for root nodule formation, because overexpression of these genes increased endogenous ABA concentration in several plant species (Audran et al. 1998; Frey et al. 1999; Thompson et al. 2000; Xiaoqiong and Jan 2002). Otherwise, to isolate a gene with the same function, it is necessary to find a mutant line which shows decreased nodule number among plants which are capable of germinating on medium containing exogenous ABA.

\section{MATERIALS AND METHODS}

\section{Construction of binary vectors.}

The coding region of TrEnodDR1, under the control of the CaMV35S promoter, was amplified by PCR and inserted into the region of the gusA gene of plasmid pBI121. The resultant plasmid was verified by DNA sequencing. The CaMV35S::
TrEnodDR1 + nos $T$ cassette of this plasmid was excised by digestion and cloned into a multiple cloning site of pHKN29 (Kumagai and Kouchi 2003) to make pHKN29-DR1. For the construction of the plasmid pIG121-Hm-DRl, the same cassette was inserted instead of the CaMV35S::gusA + nosT cassette of plasmid pIG121-Hm.

\section{Hairy root transformation and whole-plant transformation} of L. japonicus.

Hairy root transformation of L. japonicus MG20 Miyakojima (Kawaguchi 2000) with A. rhizogenes strain LBA 1334 was conducted by the method of Kumagai and Kouchi (2003). Whole-plant transformation of L. japonicus B-129 Gifu with A. tumefaciens was conducted by the method of Aoki and associates (2003).

\section{Plant materials and growth conditions.}

For growth and nodulation tests using transformed hairy roots, plants with induced hairy roots were transferred to an artificial soil mix (vermiculite/perlite, 5:1) containing B\&D medium or to a Fåhraeus agar plate $(0.9 \%)$ and inoculated with rhizobia. Growth and nodulation were analyzed 28 DAI. Most whole-plant transformants transformed with A. tumefaciens containing plasmid pIG121-Hm-DRl to express TrEnodDRI (DR1 transformants) died before setting seeds(data not shown); therefore, cuttings were used for analysis. To synchronize the growth stage of the transgenic plants, shoots of the same length (approximately $5 \mathrm{~cm}$ ) were cut and rooted in 1/200 Menedael Root Stimulator (Menedael Co., Ltd., Osaka, Japan) for 28 days. To assess growth and nodulation, these synchronized transgenic plants and synchronized wild-type plants were transferred to the artificial soil mix containing B\&D medium and inoculated with rhizobia. Growth and nodulation were analyzed 28 DAI. Abamine $(10 \mu \mathrm{M})$ was supplied to $\mathrm{B} \& \mathrm{D}$ or Fåhraeus medium for the inoculation tests.

\section{Inoculation of rhizobia.}

M. loti MAFF303099 (Kaneko et al. 2000; Saeki and Kouchi 2000) grown in yeast mannitol liquid medium (Keele et al. 1969) was harvested and then suspended in sterilized distilled water $\left(10^{8}\right.$ cells $\left./ \mathrm{ml}\right)$. Each plant was inoculated with 20 $\mu \mathrm{L}$ of suspension.

\section{Observation of root hair deformation on transformed hairy roots.}

At 14 DAI, induced hairy roots were transferred to Fåhraeus agar plates $(0.9 \%)$ in the presence or absence of $10 \mu \mathrm{M}$ abamine with $M$. loti. Seven days later, root hair deformation was observed under a microscope.

\section{Isolation of total RNA from $L$. japonicus.}

Plants and tissues were frozen quickly in liquid $\mathrm{N}_{2}$ and stored at $-80^{\circ} \mathrm{C}$. Total RNA was prepared by using the phenol-sodium dodecyl sulfate procedure (Suzuki et al. 1997) or a Plant Total RNA Extraction Miniprep System (Qiagen K. K., Tokyo).

\section{cDNA macroarray analysis.}

To compare transcriptome between wild-type $L$. japonicas and TrEnodDRl transformants, cDNA macroarray analysis was carried out by the method of Kouchi and associates (2004). For total RNA preparation, wild-type L. japonicus and TrEnodDR 1 transformant 28 days after germination were used.

\section{Analysis of gene expression by RT-PCR.}

The expression of induced genes was analyzed by one-step RT-PCR (Qiagen Inc.). After the reverse transcription reaction at $50^{\circ} \mathrm{C}$ for $30 \mathrm{~min}$ followed by heating at $95^{\circ} \mathrm{C}$ for $15 \mathrm{~min}$, the 
target gene was amplified in 30 cycles of $95^{\circ} \mathrm{C}$ for $30 \mathrm{~s}, 55^{\circ} \mathrm{C}$ for $30 \mathrm{~s}$, and $72^{\circ} \mathrm{C}$ for $30 \mathrm{~s}$. The sequences of primers were as follows: for TrEnodDR1, 5'-AACTACTATGTGCCTGACGC$3^{\prime}$ and 5'-ACAGAACTCGCCGTAAAGAC-3'; for $g f p, 5^{\prime}$-TAC GGCAAGCTGACCCTGAA- ${ }^{\prime}$ and $5^{\prime}$-TGTGATCGCGCTTC TCGTTG-3'; for rolB, 5'-GCAATCTATAGCCGTGAC-3' and 5'-GGTTCCTCCGTGCGGCTG-3'; for eIF4A, 5'-AGAGGGT TTAAAGATCAAAT-3' and 5'-ATGTCAATTCATCACGTT TT-3'; and for GUS, 5'-CAACGAACTGAACTGGCAGA-3' and 5'-GAGCGTCGCAGAACATTACA-3'. Quantitative realtime RT-PCR for the expression analysis of defense response genes in L. japonicus was carried out by the method of Shimoda and associates (2005). Primer sequences were as follows: for $P R 10.2 C, 5^{\prime}$-CCCAAAGGTTATTCCTGTTTTCA-3' and 5'ACGGTTCCGACGGCAAT-3'; for class I chitinase, 5'-TTGC TCCCCAAGTTCTCAATG-3' and 5'-GATTGGACCGCGAC CATAGT-3'; for 1,3 - $\beta$-glucanase, 5'-TGGAGCAAATGGAGA CAACCT-3' and 5'-TTCTGCTAATTCCCTTGGATTTGTA-3'; for thaumatin-like protein, 5'-GGCGGGAGGAGGTTGAAC$3^{\prime}$ and 5'-CCTGATGAGCCGGCATTC-3'; for phenylalanine ammonia lyase, 5'-CGGCGGAGGCGATGA-3' and 5'-CCAC CGGCTTCCGGTACT-3'; for chalcone synthase, 5'-TTGACC AAAGCACTTATCCTGATTT-3' and 5'-GCGCTGAAACTTC TCCTTAAGC-3'; for caffeic acid O-methyltransferase, $5^{\prime}$-CC GGTTTGGCAAACCACTT-3' and 5'-GGGAGGGTGCATCT TCAATG-3'; and for pathogen-inducible $\alpha$-dioxygenase, $5^{\prime}$ CCTGTTGTACCTTGCCATTCG-3' and 5'-TGTGCTCCCCA CGTTCAA-3'.

\section{Observation of stomatal aperture.}

Leaves of transformants were put on a slide glass coated with spray paste (3M Super 77 Spray Adhesive; 3M, St. Paul, MN, U.S.A.) to get an impression of the epidermis. The impression then was observed under the microscope.

\section{Measurement of $\mathrm{ABA}$ concentration.}

The ABA concentrations in leaves or roots were measured basically by the method of Suzuki and associates (2004). At 28 DAI, all leaves of L. japonicus treated with A. rhizogenes and randomly sampled from a whole-plant transformant were used for measurement of endogenous ABA concentration. For ABA concentration in roots, a half-volume of the hairy roots or adventitious roots was used after distinction under the fluorescence microscope.

\section{ACKNOWLEDGMENTS}

This work was supported in part by the Special Coordination Funds for Promoting Science and Technology from Ministry of Education, Culture, Sports, Science and Technology in Japan. We thank L. Suriyagoda for critical editing of the manuscript.

\section{LITERATURE CITED}

Abel, P. A., Nelson, R. S., De, B., Hoffmann, N., Rogers, S. G., Frayley, R. T., and Beachy, R. N. 1986. Delay of disease development in transgenic plants that express the tobacco mosaic virus coat protein gene. Science 232:738-743

Aoki, T., Kamizawa, A., and Ayabe, S. 2003. Efficient Agrobacteriummediated transformation of Lotus japonicus with reliable antibiotic selection. Plant Cell Rep. 21:238-243.

Audran, C., Borel, C., Frey, A., Sotta, B., Meyer, C., Simonneau, T., and Marion-Poll, A. 1998. Expression studies of the zeaxanthin epoxidase gene in Nicotiana plumbaginifolia. Plant Physiol. 118:1021-1028.

Bano, A., and Harper, J. E. 2002. Plant growth regulators and phloem exudates modulate root nodulation of soybean. Funct. Plant Biol. 29:12991307.

Bano, A., Harper, J. E., Auge, R. M., and Neuman, D. S. 2002. Changes in phytohormone levels following inoculation of two soybean lines differing in nodulation. Funct. Plant Biol. 29:965-974.
Beachy, R. N. 1990. Coat protein mediated resistance against virus infection. Annu. Rev. Phytopathol. 28:451-474.

Boccardo, G., and Candresse, T. 2005. Complete sequence of the RNA2 of an isolate of White clover cryptic virus 1 , type species of the genus $\mathrm{Al}$ phacryptovirus. J. Arch. Virol. 150:403-405.

Cho, M.-J., and Harper, J. E. 1993. Effect of abscisic acid application on root isoflavonoid concentration and nodulation of wild-type and nodulation-mutant soybean plants. Plant Soil 153:145-149.

Finkelstein, R. R., Gampala, S. S. L., and Rock, C. D. 2002. Abscisic acid signaling in seeds and seedling. Plant Cell 14:S15-S45.

Fladung, M. 1990. Transformation of diploid and tetraploid potato clones with the rolC gene of Agrobacterium rhizogenes and characterization of transgenic plants. Plant Breed. 104:295-304

Frey, A., Audran, C., Marin, E., Sotta, B., and Marion-Poll, A. 1999. Engineering seed dormancy by the modification of zeaxanthin epoxidase gene expression. Plant Mol. Biol. 39:1267-1274.

Hayashi, M., Imaizumi-Anraku, H., Akao, S., and Kawaguchi, M. 2000. Nodule organogenesis in Lotus japonicus. J. Plant Res. 112:489-495.

Hirsch, A. M., Bauer, W. D., Bird, D. M., Cullimore, J., Tyler, B., and Yoder, J. I. 2003. Molecular signals and receptors: controlling rhizosphere interactions between plants and other organisms. Ecology 84:858-868.

Jan, F.-J., Fagoaga, F., Pang, S.-Z., and Gonsalves, D. 2000a. A single chimeric transgene derived from two distinct viruses confers multi-virus resistance in transgenic plants through homology-dependent gene silencing. J. Gen. Virol. 81:2103-2109.

Jan, F.-J., Pang, S.-Z., Tricoli, D. M., and Gonsalves, D. 2000b. Evidence that resistance in squash mosaic comovirus coat protein-transgenic plants is affected by plant developmental stage and enhanced by combination of transgenes from different line. J. Gen. Virol. 81:2299-2306.

Kaneko, T., Nakamura, Y., Sato, S., Asamizu, E., Kato, T., Sasamoto, S., Watanabe, A., Idesawa, K., Ishikawa, A., Kawashima, K., Kimura, T., Kishida, Y., Kiyokawa, C., Kohara, M., Matsumoto, M., Matsuno, A., Mochizuki, Y., Nakayama, S., Nakazaki, N., Shimpo, S., Sugimoto, M., Takeuchi, C., Yamada, M., and Tabata, S. 2000. Complete genome structure of the nitrogen-fixing symbiotic bacterium Mesorhizobium loti. DNA Res. 7:331-338.

Kawaguchi, M. 2000. Lotus japonicus 'Miyakojima' MG20: an earlyflowering accession suitable for indoor handling. J. Plant Res. 113:507509.

Keele, B. B., Jr., Hamilton, P. B., and Elkan, G. H. 1969. Glucose catabolism in Rhizobium japonicum. J. Bacteriol. 97:1184-1191.

Kouchi, H., Shimomura, K., Hata, S., Hirota, A., Wu, G. J., Kumagai, H. Tajima, S., Suganuma, N., Suzuki, A., Aoki, T., Hayashi, M., Yokoyama, T., Ohyama, T., Asamizu, E., Kuwata, C., Shibata, D., and Tabata, S. 2004. Large-scale analysis of gene expression profiles during early stages of root nodule formation in a model legume, Lotus japonicus. DNA Res. 11:263-274

Krusell, L., Madsen, L. H., Sato, S., Aubert, G., Genua, A., Szczyglowski, K., Duc, G., Kaneko, T., Tabata, S., de Bruijin, F., Pajuelo, E., Sandal, N., and Stougaard, J. 2002. Shoot control of root development and nodulation is mediated by a receptor-like kinase. Nature 420:422-426.

Kumagai, H., and Kouchi, H. 2003. Gene silencing by expression of hairpin RNA in Lotus japonicus roots and root nodules. Mol. Plant-Microbe Interact. 16:663-668.

Ma, W., Guinel, F. C., and Glick, B. R. 2003. Rhizobium leguminosarum biovar viciae 1-aminocyclopropane-1-carboxylate deaminase promotes nodulation of pea plants. Appl. Environ. Microbiol. 69:4396-4402.

Nilsson, O., Moritz, T., Imbault, N., Sandberg, G., and Olsson, O. 1993. Hormonal characterization of transgenic tobacco plants expressing the rolC gene of Agrobacterium rhizogenes TL-DNA. Plant Physiol. 102:363-371

Nishimura, R., Hayashi, M., Wu, G. J., Kouchi, H., Imaizumi-Anraku, H., Murakami, Y., Kawasaki, S., Akao, S., Ohmori, M., Nagasawa, M., Harada, K., and Kawaguchi, M. 2002a. HAR1 mediates systemic regulation of symbiotic organ development. Nature 420:426-429.

Nishimura, R., Ohmori, M., and Kawaguchi, M. 2002b. The novel symbiotic phenotype of enhanced-nodulating mutant of Lotus japonicus: astray mutant is an early nodulating mutant with wider nodulation zone. Plant Cell Physiol. 43:853-859.

Niwa, Y., Hirano, T., Yoshimoto, K., Shimizu, M., and Kobayashi, H. 1999. Non-invasive quantitative detection and applications of nontoxic, S65T-type green fluorescent protein in living plants. Plant J. 18:455463.

Nukui, N., Ezura, H., Yuhashi, K.-I., Yasuta, T., and Minamisawa, K. 2000. Effects of ethylene precursor and inhibitors for ethylene biosynthesis and perception on nodulation in Lotus japonicus and Macroptilium atropurpureum. Plant Cell Physiol. 41:893-897.

Nukui, N., Ezura, H., and Minamisawa, K. 2004. Transgenic Lotus japonicus with an ethylene receptor gene $\mathrm{Cm}-\mathrm{ERS} / \mathrm{H} 70$ enhances for- 
mation of infection threads and nodule primordia. Plant Cell Physiol. 45:427-435.

Oldroyd, G. E. D., Engstrom, E. M., and Long S. R. 2001. Ethylene inhibits the Nod factor signal transduction pathway of Medicago truncatula. Plant Cell 13:1835-1849.

Oono, Y., Handa, T., Kanaya, K., and Uchimiya, H. 1987. The TL-DNA gene of Ri plasmids responsible for dwarfness of tobacco plants. Jpn. J. Genet. 62:501-505.

Penmetsa, R. V., and Cook, D. R. 1997. A legume ethylene-insensitive mutant hyperinfected by its rhizobial symbiont. Science 275:527-530.

Phillips, D. A. 1971. Abscisic acid inhibition of root nodule initiation in Pisum sativum. Planta 100:181-190.

Saeki, K., and Kouchi, H. 2000. The Lotus symbiont, Mesorhizobium loti molecular genetic techniques and application. J. Plant Res. 113:457-465.

Schmülling, T., Schell, J., and Spena, A. 1988. Single genes from Agrobacterium rhizogenes influence plant development. EMBO (Eur. Mol. Biol. Organ.) J. 7:2621-2629

Searle, I. R., Men, A. E., Laniya, T. S., Buzas, D. M., Iturbe-Ormaetxe, I. Carroll, B. J., and Gresshoff, P. M. 2003. Long-distance signaling in nodulation directed by a CLAVATA1-like receptor kinase. Science 299:109-112.

Shimoda, Y., Nagata, M., Suzuki, A., Abe, M., Sato, S., Kato, T., Tabata S., Higashi, S., and Uchiumi, T. 2005. Symbiotic rhizobium and nitric oxide induce gene expression of non-symbiotic hemoglobin in Lotus japonicus. Plant Cell Physiol. 46:99-107.

Shinozaki, K., and Yamaguchi-Shinozaki, K. 2000. Molecular responses to dehydration and low temperature: differences and cross-talk between two stress signaling pathways. Curr. Opin. Plant Biol. 3:217-223.

Sun-Young, H., Kitahata, N., Sekimata, K., Saito, T., Kobayashi, M.,
Nakashima, K., Yamaguchi-Shinozaki, K., Shinozaki, K., Yoshida, S., and Asami, T. 2004. A novel inhibitor of 9-cis-epoxycarotenoid dioxygenase in abscisic acid biosynthesis in higher plants. Plant Physiol. 135:1574-1582.

Suzuki, A., Suzuki, T., Tanabe, F., Toki, S., Washida, H., Wu, C.-Y., and Takaiwa, F. 1997. Cloning and expression of five myb-related genes from rice seed. Gene 198:393-398.

Suzuki, A., Kobayashi, F., Abe, M., Uchiumi, T., and Higashi, S. 2001 Cloning and expression of a down-regulated gene (TrEnodDR1) of white clover responded by the nod genes derived from Rhizobium leguminosarum bv. trifolii strain 4S [sic]. Gene 266:77-84.

Suzuki, A., Akune, M., Kogiso, M., Imagama, Y., Osuki, K., Uchiumi, T., Higashi, S., Han, S.-Y., Yoshida, S., Asami, T., and Abe, M. 2004. Control of nodule number by the phytohormone abscisic acid in the roots of two leguminous species. Plant Cell Physiol. 45:914-922.

Thompson, A. J., Jackson, A. C., Symonds, R. C., Mulholland, B. J. Dadswell, A. R., Blake, P. S., Burbidge, A., and Taylor, I. B. 2000. Ectopic expression of a tomato 9-cis-epoxycarotenoid dioxygenase gene causes over-production of abscisic acid. Plant J. 23:363-374.

Uno, Y., Furihata, T., Abe, H., Yoshida, R., Shinozaki, K., and YamaguchiShinozaki, K. 2000. Arabidopsis basic leucine zipper transcription factors involved in an abscisic acid-dependent signal transduction pathway under drought and high-salinity conditions. Proc. Natl. Acad. Sci. U.S.A. 97:11632-11637.

Xiaoqiong, Q., and Jan, A. D. Z. 2002. Overexpression of a 9-cis-epoxycarotenoid dioxygenase gene in Nicotiana plumbaginifolia increases abscisic acid and phaseic acid levels and enhances drought tolerance. Plant Physiol. 128:544-551.

Zhu, J. K. 2001. Plant salt tolerance. Trends Plant Sci. 6:66-71. 